Borneo Journal of Sciences \& Technology, 4(1): 26-36

DOI: http://doi.org/10.3570/bjost.2022.4.1-05

e-ISSN: 2672-7439

(C) 2018, UTS Publisher.

Submitted: $16^{\text {th }}$ November $2021 \quad$ Accepted: $20^{\text {th }}$ December $2021 \quad$ Published: $31^{\text {st }}$ January 2022

\title{
A System to Ensure Safety while Switching High Voltage Switchgears
}

\author{
${ }^{1,2}$ Prashobh Karunakaran, ${ }^{1,2}$ M. Shahril Osman, ${ }^{3}$ Prashanth Karunakaran, ${ }^{3}$ Shanthi Karunakaran, \\ ${ }^{4}$ Arjun Karunakaran, ${ }^{2}$ Kwong Hieng Ting, ${ }^{2}$ Alexon John
}
${ }^{1}$ Centre of Research for Innovation and Sustainable Development, University of Technology Sarawak, Sibu, 96000, Malaysia
${ }^{2}$ School of Engineering \& Technology, University of Technology Sarawak, Sibu, 96000, Malaysia
${ }^{3}$ Swinburne University of Technology, 93350, Kuching
${ }^{4}$ National Institute of Technology, 0591275, Tomakomai, Japan

\begin{abstract}
Normally high voltage switchgears are well-built, but accidents do occur and when that happens the consequences are high in terms of fatalities as well as damaging big sections of electrical systems. It is therefore imperative that such switching should be done from a safe distance away. The local electrical authority did try to build such a system with an electric motor, but it failed to pull the lever of the Lucy brand $11 \mathrm{kV}$ switchgear which is the most common one used in Sarawak. In this research an electropneumatic system was built to successfully pull the $11 \mathrm{kV}$ switchgear handle down as well as up. It was later adapted to rake-in and rake-out a $33 \mathrm{kV} \mathrm{VCB}$ switchgears and also trigger a push-button to simulate triggering such types of switchgear. The developed system allows all these operations to be done from $25 \mathrm{~m}$ away. The push-button types look safe, but the mechanical systems of breaking are still the same within it; faulty mechanisms can still cause arcs which can shoot out through the thin panel and injure the personnel.
\end{abstract}

Keywords: Electropneumatic, HV switchgears, switching, arc-quenching, motorized switchgears.

\section{INTRODUCTION}

As for most accidents, high voltage (HV) switching accidents are to a high percentage caused by a lack of understanding of the system [1]. The way switching personnel (SP) can avoid accidents are by observing any small change from the normal sequence of the switching operation; some SPs are trained to run whenever such changes happen. Examples of this are triggering not happening as expected, a small damage to the switchgear, the oil or SF6 level indicator being blurred. But there can be unexpected situations also, the indicator could be spoiled or the change in mechanical integrity not resulting in any significant changes to the operation. Overall, the safest thing to perform HV switching is to trigger the HV switchgear from a safe distance away and this research output was to enable SP to perform it from up to $25 \mathrm{~m}$ away.

In the Sarawak grid as in most other grids, only $11 \mathrm{kV}$ switchgears are operated manually, $33 \mathrm{kV}, 132 \mathrm{kV}$ $275 \mathrm{kV}$ switchgears are normally remotely operated from the State Control Centre (SDC) of the Local Electrical Authority (LEA) [2].

The HV switchgear system built in this research was successfully tested to switch the Lucy brand $11 \mathrm{kV}$ switchgear which is the most common one used in the Sarawak Grid. It was later tested to rake-in and rakeout a cubicle type switchgear which are normally rated at $33 \mathrm{kV}$ but that particular one was rated at $11 \mathrm{kV}$ [3]. The $11 \mathrm{kV}$ switchgears are mostly located in Ring Main Units (RMU) all over the state. The RMU are the intake stations from $11 \mathrm{kV}$ or $33 \mathrm{kV}$ lines to low voltage loads like housing estates, shopping centers etc. [4]. It must be noted that it takes a very strong person to pull the Lucy brand switchgears. During the initial test a $4 \mathrm{~mm}^{2}$ cable was used to fasten the pneumatic cylinder to the switchgear handle. Tight triple knots were made but the force was so strong that the knots came loose. Then a cable camp and steel wire rope was used and it worked well. Many different pneumatic cylinders were purchased. Initially the problem was insufficient length. Later it was discovered that the force was insufficient despite using a $2.5 \mathrm{HP}$ air pump. So a larger diameter pneumatic cylinder was purchased. According to equation 1 the larger surface area of the cylinder can provide greater force [5].

$$
\mathrm{F}=\mathrm{PA}
$$




\section{A System to Ensure Safety while Switching High Voltage Switchgears}

Where $\mathrm{F}=$ force, $\mathrm{P}=$ pressure and $\mathrm{A}=$ surface area of the piston. The final successful operation is depicted in Fig. 11. Next the system was tried on a cubicle type VCB (vacuum circuit breaker). It was noticed that for the initial movement the system cannot actuate but with a little help with a human hand, the rest of the process worked well. But with the bigger diameter cylinder, the whole actuation process worked smoothly. The base of the bigger pneumatic cylinder which was made of 3 $\mathrm{mm}$ aluminum gave way due to the much stronger force exerted by the bigger $\varnothing$ pneumatic cylinder, so this was replaced with a stronger steel structure. The successful racking-in and racking-out of the VCB is depicted in Fig. 12.

The latest HV switchgears are designed such that a small push button will trigger a motor to actuate the switchgear. Though this setup looks neat and safe, the danger from improper mechanical actuation from things like an insufficiently greased shaft can still cause a large arc that can easily pierce through the $2-3 \mathrm{~mm}$ cubicle switchgear body, resulting in fatality [6];[7]. Therefore, the finger pushing in front of a cubicle switchgear needs to be replaced by an actuator performing it and the human triggering it from up to $25 \mathrm{~m}$ away.

\section{LITREATURE REVIEW}

In all electrical switching there is a formation of an arc. Even the ubiquitous switch to turn on lights at homes will have arching upon switching on or off. But in HV switches, the arcs are very powerful and if not controlled, it can immediately burn through thick enclosures as if there are none. Arcs are like lightning which is one of the most powerful forces of nature. If energy can be tapped from lightning, a single lightning can power the whole earth for 20 years. Typically, lightning is between $5-10 \mathrm{kHz}$ and can reach as high as $300 \mathrm{Mhz}$ and can reach up to $50 \mathrm{~km}$. The arcs from HV switchgears must be treated with similar respect to lightings [8-10].

Arc quenching protocol is basically to blow the arc such that it becomes as thin and long as possible. Thick arcs are dangerous. And arc splitters are placed at the side to which arcs are blown to break it down; hence the name; they are basically plates arranged in the pathway of the thinned arc such that it will be split up [11]. What is blown onto the arc has evolved from air to insulating oil to currently mostly $\mathrm{SF}_{6}$ [12]. Another arc quenching method is to split the contact point from one to many; this will reduce voltage in each contact and therefore the thickness of the arc.

One fact a SP must always be aware of is that breaking a HV switchgear is about 2.5 more dangerous than closing it [12];[13]. Table 1 is a typical spec for an $11 \mathrm{kV}$ switchgear.
The right column is the rated making and breaking current. It can be noticed that the making current is $68 \mathrm{kA}$ while the breaking current is $26.3 \mathrm{kA}$. This means it is safer to do a making than a breaking and since:

$$
\frac{68 \mathrm{kA}}{26.3 \mathrm{kA}}=2.58
$$

This means the breaking is 2.58 times more dangerous than the making [12].

Table 1: Typical specifications of a HV switchgear

\begin{tabular}{|l|l|}
\hline Rated voltage & $3.6-12.2 \mathrm{kV}$ \\
\hline Continuous current & $400-1590 \mathrm{~A}$ \\
\hline Rated interrupting current & $26.3-43 \mathrm{kA}$ \\
\hline Rated making current & $68 \mathrm{kA}$ \\
\hline Rated short time current & $26 \mathrm{kA}$ for $3 \mathrm{~s}$ \\
\hline
\end{tabular}

The material used to blow onto the arc can also be ionized because exerting an arc onto a material is the method of converting atoms to ions [14]. For example, ionizers which are sold in markets or especially within refrigerators to preserve vegetables basically use the principle of pushing air over an arc. So, blowing insulating oil onto an arc will eventually convert the oil atoms to ions. The speed of blowing cools the oil down which helps to convert some of the ions formed back into atoms. This is why one of the procedures for the SP in Sarawak is, once in six months, they have to open a nut at the bottom of the OCB and drain out a little of the oil to test it [16]. The test done is dielectric strength as well as moisture level. Moisture level test is necessary because most OCB are placed in the open environment where rainwater can eventually seep in [16]. But in the opinion of this author the test should not be once in six months but according to how many times the switchgear was switched. This is because it is the switching that causes the ionization. It must be noted that all ions, even for the best insulator atoms, are good conductors [17]. $\mathrm{SF}_{6}$ has been found to be one of the best materials to blow onto the arc because the bonds between the sulfur atom and the six fluorine atoms are one of the strongest in nature. Besides, both sulfur and fluorine are cheaply found and therefore $\mathrm{SF}_{6}$ can be easily manufactured. But the United Nations is worried about it because $\mathrm{SF}_{6}$ has the highest climate change potential among all gasses; it is 22,000 worse than $\mathrm{CO}_{2}$ over a period of 100 years. $\mathrm{CO}_{2}$ will mostly get dissolved in the ocean over 20-200 years but $\mathrm{SF}_{6}$ breaks down only between 800-3200 years [18].

The future of HV switching is being worked upon by N.C. State University. The system developed by them 


\section{A System to Ensure Safety while Switching High Voltage Switchgears}

utilizes insulated gate bipolar transistors (IGBT). But the highest voltage capability of these devices is $3 \mathrm{kV}$ so the solution is to break down say $10 \mathrm{kV}$ into three, each will switch a third of the voltage. This can be done because the frequency of standard AC is $50 \mathrm{~Hz}$ or $20 \mathrm{~ms}$ per cycle which is very slow compared to the speed of power electronic switching. So, when voltage is zero is detected, the first 1/3 of the voltage wave is switched. At exactly:

$$
\frac{20 \mathrm{~ms}}{6 \mathrm{~ms}}=3.3 \mathrm{~ms}
$$

another IGBT is switched and after $6.67 \mathrm{~ms}$ the third is switched. This way, with three IGBTs the entire $10 \mathrm{kV}$ can be switched by splitting the voltage over time. It must be noted that IGBT switching occurs over a period of just about $1 \mu \mathrm{S}$ compared to a switching time of OCB of about $0.1 \mathrm{~s}$. Therefore, the IGBT switch switches:

$$
\frac{0.1 S}{1 \times 10^{6} \mathrm{~s}}=100,000 \text { times faster }
$$

With such speed of switching, all the arc quenching mechanisms are not necessary [19]. The end result is a whole RMU which typically occupies a land area of about 7 X 5m in Sarawak can be reduced to about $1 \mathrm{X}$ $1 \mathrm{~m}$, thereby enabling:

1) Much increased safety.

2) Much reduced land requirement.

3) Much reduced cost.

For a new housing estate, a contractor stated that a RMU cost MYR5 million including equipment, land area and LEA fees. Comparatively a 1 X $1 \mathrm{~m}$ of electronics will be very much cheaper [17].

The next few paragraphs describe the HV switching accidents which have occurred so far.

Most electrical power engineering lecturers show their students a HV switching accident which was captured by CCTV. It was a racking-in accident where the SP perished. In most systems, racking-in and racking-out is done manually by holding the two handles of the unit containing the VCB. But in some systems, a screwing mechanism replaces the human hands pushing the unit in, to lighten the manual force exertion. In that particular video on YouTube the screwing mechanism was utilized. It lightens the human effort but decreases the human's sensitivity to any abnormal conditions. For example, at one time cars were fitted with active suspension where motorized suspension adjusts perfectly according to data from a distance sensor placed before the wheel of the car. Such cars can even ride on a railway track without the passenger feeling bumps. But the wheel and other mechanism will get damaged upon hitting a sharp obstruction. Similarly, if the sensitivity to changes in movement during the rackingin is not felt by the SP as when a screw mechanism is used, disasters like shown on that YouTube video can happen [2].

In 1993, in Texas a SP raked-in a VCB. This caused the three supply contacts to be joined to the three load contacts. After that he actuated a lever that is supposed to close the VCB contacts. But the indicator did not show that the VCB was closed. So he started rackingout the VCB, but by this time the VCB contacts closed. What happened is that the shaft of the VCB was not greased enough so it was slow to close. By the time it closed, the SP had pulled the VCB unit out a little, thereby separating the main contacts a little. For an arc to jump $1 \mathrm{~cm}$ requires $30 \mathrm{kV}$ and therefore $60 \mathrm{kV}$ for 2 $\mathrm{cm}$. The SP pulled the unit about $1-2 \mathrm{~cm}$ creating a powerful arc. Assume this arc is about $50 \mathrm{kV}$. Without arc-quenching, this $50 \mathrm{kV}$ will try to find ground as all electrons are looking for ground because the ground is $\mathrm{SiO}_{2}$. Both $\mathrm{Si}$ and $\mathrm{O}_{2}$ are electron loving. Plus $\mathrm{SIO}_{2}$ is a semiconductor with $\Omega / \mathrm{cm}^{3}=200 \mathrm{k}$ compared to $\mathrm{Cu}$ $\Omega / \mathrm{cm}^{3}=1.7 \mu \Omega$. Therefore, all electrons from lighting as well as power systems are always heading for the earth. $\mathrm{SiO}_{2}$ differs from if the earth was a ball of plastic where only the very top layers of atoms will want electrons and the electron needs of the atoms below the surface cannot attract the lightning because plastic is an insulator. For the $\mathrm{SiO}_{2}$ earth, even atoms deep inside earth can contribute to the attractive force for the electrons of lightning [9]. So the $50 \mathrm{kV}$ arc will be jumping to the cubicle. All switchboard metal works are grounded to a spec of $<1 \Omega$ which will be very attractive to a $50 \mathrm{kV}$ arc. It all happens in a split second, it touches the first point of the cubicle and that vertical pathway to ground became full to it moves to the next, thereby moving it all around the $10 \mathrm{~m}$ plus cubicle switchgear and also use the bodies of the SP and his supervisor (who was standing behind him) to reach ground; killing them instantly as they were thrown to the wall behind. As the arc travelled around the $10 \mathrm{~m}$ of cubicle switchgear, it also seriously injured three other personnel [9].

A third accident occurred in Sibu, Malaysia. A SP noticed via the oil level indicator that the oil was low in the $11 \mathrm{kV}$ OCB. But he was somehow in a hurry and just performed the switching anywhere thinking that amount of oil was sufficient. Burnt oil splashed onto him giving him second degree burns plus when he was almost recovered, he received a warning letter from the LEA because he did not put on the PPE (personnel protective equipment) which was specified as the $69 \mathrm{Cal}$ Arc Flash Protection suit. This author was teaching a class of about 30 SPs from the LEA, and all stated that it is too hot to wear this protection in Malaysia. They cannot even see through the clear face shield because of all the mist building up inside. Therefore, the next research project of this author is to build a small airconditioner which can be placed inside the suit. Another learning from this accident is that it is very critical that 


\section{A System to Ensure Safety while Switching High Voltage Switchgears}

the arc is blown to exactly the right length and thinness. If these two specs are not met due to insufficient oil, an explosion can result [7].

A third example of HV switching accident happened in 1994 which resulted in the death of four SPs one of which was a classmate of this author while he studied electrical engineering in the USA. He came back to KL and worked for Tenaga Nasional. All four went for a troubleshooting of an $11 \mathrm{kV}$ OCB and switched it. The switchgear exploded, killing all four. After a detailed investigation, it was discovered that the fuse in the switchgear was jumped with a copper wire. There was an electrical problem downline from this switchgear which caused it to trip. The previous SP was frustrated to change the fuse each time, so he jumped it with a copper wire [12].

A fourth example of switchgear exploding happened in Bintulu, Malaysia. The gauge indicator for the $\mathrm{SF}_{6}$ level was blur so the SP could not determine if there was sufficient $\mathrm{SF}_{6}$. He switched it anyway and there was an explosion but luckily the SP did not receive any injury. It must be noted that the switchgear was made by Siemens which is a 173-year-old company and the second biggest electric parts company on earth. If such a company cannot keep $\mathrm{SF}_{6}$ in a container, it is a logical assumption that no other company can do so. So all SP must assume that SF6 can leak out of switchgears. In a switchgear the container must have a shaft going in and out of it to accomplish the actuation and the leakage is via its $\mathrm{O}$ rings [9].

\section{MATERIALS AND METHODS}

The first activity in designing this HV switchgear switching system is to design which mode of actuation to use. The options are motors with lead screws, pneumatics, and hydraulics. Of these, hydraulics is messy because leaking hydraulic fluids and odor in the SP's car won't be acceptable to them.

Worldwide, most actuations have increasingly moved to electric motors turning lead screws [20]. So, for the largest HV switchgears, push buttons are now pressed to get a motor to turn a lead screw which will pull the switchgear lever [21].

The LEA tried to develop a switchgear switching system with similar basic concepts as this research but using an electric motor. It was not powerful enough to pull the $11 \mathrm{kV}$ Lucy brand OCB's lever [17]. Therefore, either the coiling of the motor must be designed to handle such force, or a variable frequency drive (VFD) must be used to control the motor's force. Comparatively a simple air controller as shown in Fig. 1 left is used to control the force of a pneumatic cylinder in this research. The air valve on the left of Fig. 1 is to prevent air leakage from the pneumatic tank once it is filled. The pneumatic pump, the yellow one shown in
Fig. 10 left image is placed between the back seat and the passenger seat. This is a proper location for it in a car because it will not tip over. If it tips over, lubricating fluid will leak out.
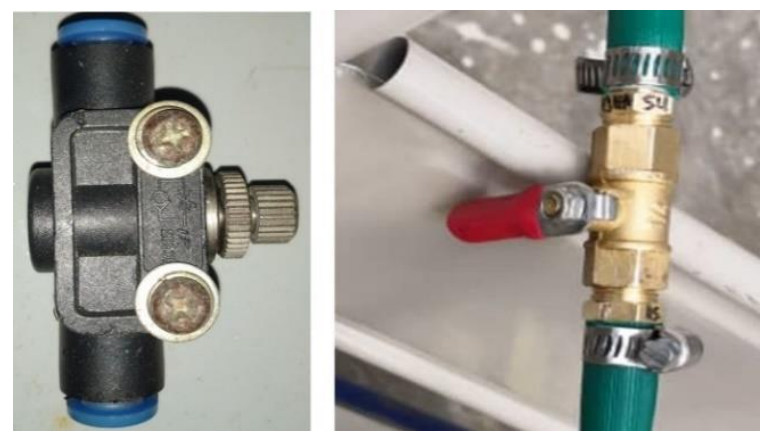

Fig. 1: Air pressure tuners which vary the force of pneumatic cylinders.

The LEA also used a heavy base and not the yellow ratchet rope shown in Fig. 11 in this research. It is however a fallacy to think motors are not capable of such force in this age when electric motors are used for electric cars, the propellers of the largest ships, the largest cranes (used by $O \& G$ industry) and even the giant trucks used in Australian mines (where a standing human is only half the height of the wheel) [22-24]. The current largest induction motor is 186,000 $\mathrm{HP}$ and is used in India for irrigation [3]. Heavy industries have long realized the actuation efficiency of the induction motor invented by Nikolai Tesla is much superior to hydraulics. But VFDs are simply not priced right. In the Western Digital factory in Kuching a $5 \mathrm{HP}$ one cost $\$ 1,500$ [3]. Most oil palm mills in the country use a 40 HP one which costs $\$ 10,000$. And a university in Kuching uses a $\$ 20,000$ one for its centralized airconditioning [3]. The advantage of a VFD is that it can start a motor with a perfect curve of voltage increasing over time starting from zero going up [25]. For an autotran, the voltage jumps straight up to half and six seconds later it jumps straight up to before full (415V) [3]. But many modern motors already have varnish and ball bearings (the only two parts that can fail in an induction motor) that can take the electrical and mechanical stress of starting a large motor. The quality of these have improved over time such that large companies like Shell Sarawak already use contactors which are about one meter wide for directly (DOL or Direct on-line), meaning there is no reduction of voltage, and the full voltage goes into the motor directly [3]. VFDs are optimum for a process like at WD Kuching where a particular speed is required for 20s, another speed for $30 \mathrm{~s}$ and another for $40 \mathrm{~s}$. Comparatively starters can only reduce the voltage, but 


\section{A System to Ensure Safety while Switching High Voltage Switchgears}

the speed is the LEA's speed which is $50 \mathrm{~Hz}$ or 1500 RPM [3].

In fact, the price of VFD is so high that even in the construction of large ships or trains propelled by electric motors, VFDs are not chosen and instead cycloconverters are preferred. In cycloconverters, the oldest electronic component ever invented is used, namely the diode [3]. In cycloconverters, diodes are used to cut off a certain number of positive $\mathrm{AC}$ waveforms and a certain number of negative $\mathrm{AC}$ waveforms. This will result in a new frequency which is lower. This is thereby a method of reducing the speed of large motors. For example, for $50 \mathrm{~Hz} \mathrm{AC}$, for six consecutive positive and negative waveforms, if the $1^{\text {st }}$ and $3^{\text {rd }}$ positive waves are chopped off then the $6^{\text {th }}$ and $8^{\text {th }}$ negative wave are chopped off the resulting waveform will see high on the negative side over two cycles and then high on the positive side over the next two cycles [3]. That is, the new speed will be:

$$
\frac{1}{4} X 50 \mathrm{~Hz}=12.5 \mathrm{~Hz}
$$

Since most motors are four pole ones, the speed is if connected to $50 \mathrm{~Hz}$ supply is:

$$
\begin{aligned}
& \mathrm{N}_{s}=\frac{1201}{\mathrm{P}} \\
& \mathrm{N}_{\mathrm{s}}=\frac{120(50)}{4}=1500 \mathrm{RPM}
\end{aligned}
$$

and with a cycloconverter above the speed will be:

$$
\mathrm{N}_{\mathrm{s}}=\frac{120(12.5)}{4}=375 \mathrm{RPM}
$$

The only problem with electropneumatic systems is that once an actuation is triggered, it cannot stop in-between. For motors with a closed loop system as with a VFD, encoders provide feedback of the exact location of the motor rotor, the actuation can be stopped at a precise location. But for OCB, ACB and any HV switchgears, stopping actuation in-between is very dangerous. Even for a push-button type HV switchgear, the push button must be pushed with a steady push and not a nervous push-retract-type of movement of the finger. The reason for the danger in stopping halfway is that the contacts are separated over a longer time period than necessary. For an arc to be able to jump over $1 \mathrm{~cm}$, the voltage is $30 \mathrm{kV}$ even though the voltage it is switching is $11 \mathrm{kV}$ [26]. Arcs accumulate in voltage before jumping. It must be noted that the clearance distance for $60 \mathrm{kV}(2$ $\mathrm{cm}$ separation) is more than 10 feet. Therefore, an electropneumatic system which do not stop at all after actuation is the best, making electropneumatics optimum [27].
Electropneumatics have been around for a long time and therefore the components have been time-tested. Fig. 2 is the schematic used in this design [28].

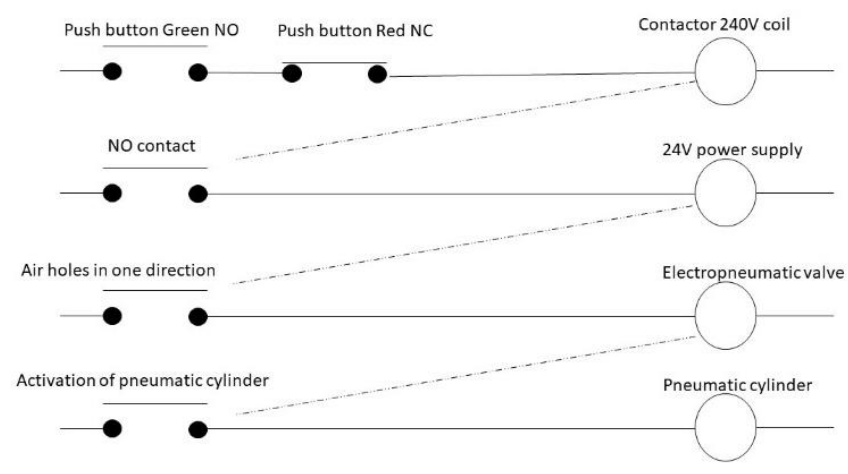

Fig. 2: Electropneumatic circuit diagram. The pneumatic pipes (Fresto brand) and the air pressure fittings are of $6 \mathrm{~mm} \varnothing$.

In Fig. 2, when the push button is pushed, $240 \mathrm{~V}$ will enter the coil of the contactor, turning it into a solenoid. This will pull down the contactor contacts which will join the $24 \mathrm{~V}$ from the power supply to go through the NO to energize the electropneumatic valve as shown in Fig. 4. The coil in the electropneumatic valve will turn into a solenoid and pull the shaft within it as shown in Fig. 3 towards it. The other end of it is a spring so if the solenoid is not a magnet, it will spring-return. The shaft has milled portions such that the 60-psi air can move from one hole to another before the solenoid is activated and from another hole to another when the spring pulls the shaft back. The way to design such movements is electropneumatic diagrams similar to the diagram drawn on the electropneumatic valve of Fig. 4. Two push buttons were used. The Green push button will extend the pneumatic cylinder and the Red pushbutton will retract the pneumatic cylinder.

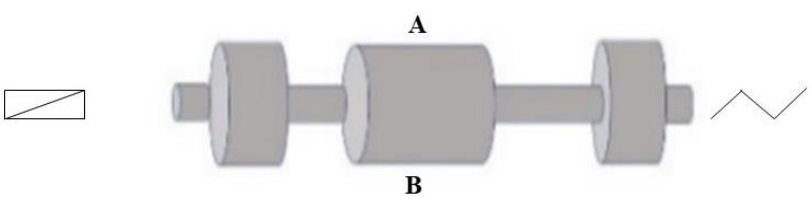

Fig. 3: The shaft within an electropneumatic valve which is actuated by a solenoid on the left and spring on the right. 


\section{A System to Ensure Safety while Switching High Voltage Switchgears}

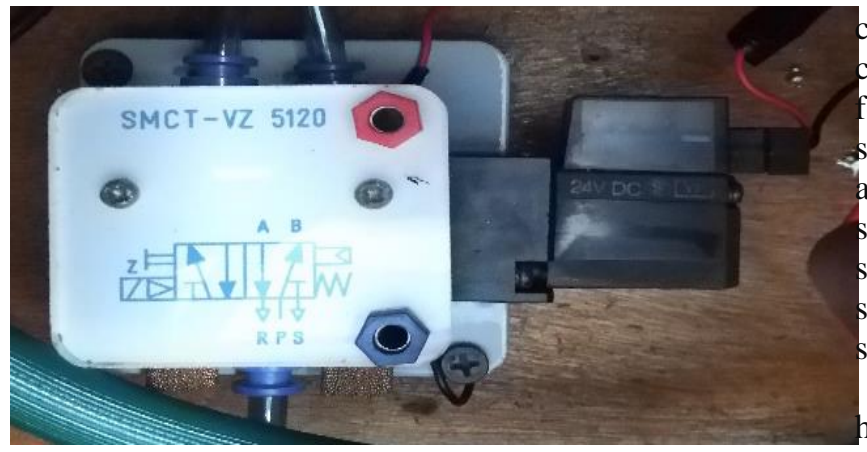

case in Texas, a lack of lubrication in the shaft can occur causing the contact points to be separated for about $1 \mathrm{~cm}$ or a sustained period. Therefore, even push-button type witchgears need to be actuated from a safe distance away. In fact, SP stated that the procedure for HV switching is that if anything abnormal happens they should run which is why the substation room door should always be open while they perform the witching.

The first complication of this research was how to hold down the pneumatic cylinder as it is performing the actuation. Obviously the first thought is that a heavy

Fig. 4: The electromagnetic valve. At the middle are the red and black terminals to energize the coil with 24V DC.

Two pumps were installed in the system. One is $0.25 \mathrm{HP}$ which is shown in Fig. 8 left, the shiny one at the right of the box. The other pump $2.5 \mathrm{HP}$ as shown in Fig. 8, the yellow one in the middle bottom. This pump can generate a pressure of 7 atm (102 psi).

The 0.25 HP pump was tested to be capable of switching the Lucy brand $11 \mathrm{kV}$ switchgear, but it got quite hot after the process of actuation; it was actually too hot for a human hand to touch. The air coming out of it was also too hot for the human hand. But this is a backup pump in case the 2.5HP one fails. The advantage of the $0.25 \mathrm{HP}$ pump is that it can be powered from the cigarette lighter of a standard car. The jack for connecting this pump to the car cigarette lighter is placed in the box. The 0.25 HP pump can also be used for small actuations such as pushing a push button for the most modern HV switchgears.

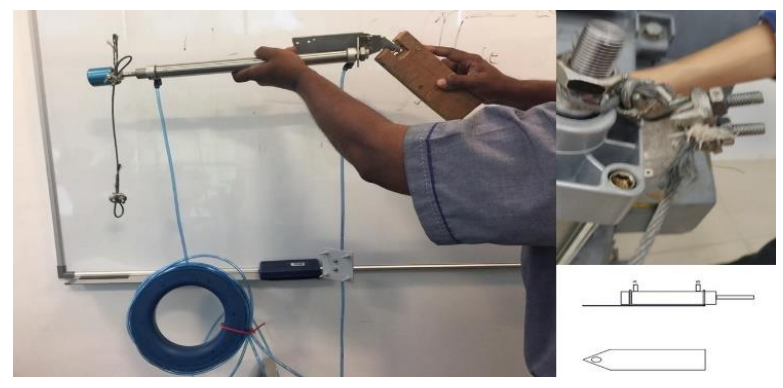

Fig. 5: Right is the full setup of the pneumatic cylinder.

Wire rope is attached to the actuation portion of the cylinder with a wire rope fastener. Left depicts the two wire rope fasteners used. Bottom right is the schematic of the pneumatic cylinder holder which is designed to have maximum degrees of freedom for the cylinder.

It is a general opinion that the push button type of switchgear is safer since actuating it is similar to punching a laptop key but the mechanical engineering beyond the push button is the same as that found in a Lucy Switchgear which requires a very strong person to pull the lever. As in the previously described accident base will be required but this is not practical as the SP will not want to carry the heavy base therefore after a long brooding, the truck ratchet rope was decided upon.

The next complication was the design of the holder of the pneumatic cylinder. Because of the great force required to pull the Lucy brand $11 \mathrm{kV}$ switchgear a good degree of freedom must be provided at the joint between the holder and the pneumatic cylinder. As an indication of the force required to pull the switchgear lever, initially the switchgear was tied to the top of the pneumatic cylinder with $4 \mathrm{~mm}^{2}$ wire with a knot, then a double knot and a triple knot, yet the knot came loose. It was then decided that the wire rope fastened together with wire rope fasteners as shown in Fig. 5 is the optimum way to fasten the switchgear lever to the pneumatic cylinder. So, two wire rope fasteners are used, one to secure it around the pneumatic cylinder and another to fasten it to the lever of the switchgear. A number 13 ratchet spanner is optimum to fasten the wire rope fastener. A big combination plier is needed to hold the wire rope fastener as its nuts are being fastened, preferably a big monkey plier. It must be noted that the wire rope as shown in Fig. 5 can easily open up into the individual strands of steel wires and these are very sharp and can injure the fingers, hence the need for sturdy monkey pliers. The finalized design to provide a high degree of freedom is shown in Fig. 5 left bottom. Five pieces of plywood were fastened together with screws. This formed a rectangular block of dimensions 8 " X 3.5 ". Then a 1.5 " X 2" rectangular portion was cut off from the top. The bottom of the pneumatic cylinder was a metal base which was made of $2 \mathrm{~mm}$ aluminum. This aluminum was rectangular with one end cut to shape like a pointing arrow as shown in Fig. 5 right bottom. A hole was drilled into this arrow shape portion. Then a hole was then drilled in the block of plywood past the cut out 1.5" X 2". A long nail was pushed through this hole and through the hole in the aluminum base's hole. This provided the pneumatic cylinder a wide degree of freedom as shown in Fig. 5 left.

During the test the first ratchet rope broke so a ratchet rope which can carry the highest load was purchased and this worked. The price for this was just three times the previous one. After this was done, it was 


\section{A System to Ensure Safety while Switching High Voltage Switchgears}

noticed that despite the actuation of the Lucy brand $11 \mathrm{kV}$ switchgear happening, the force should be further increased. Following the equation below, it can be determined that to get greater force, the A can be increased. A pneumatic cylinder with a larger crosssectional area was purchased from Amazon and as predicted, the force was obviously bigger. With this equation (1), the triggering of the Lucy brand switchgear was considered successful.

The next step was to use the system to rack-in and rack-out a VCB unit. An $\varnothing=6 \mathrm{~mm}$ hole was drilled into the plywood base. Then a cement drill bit of $\varnothing=6 \mathrm{~mm}$ was drilled into the floor in-front of the VCB. A nail of length 8 " was lightly hammered through the wood base and the hole in the floor. Upon actuation, the wood base turned in a circle. So, another hole was drilled into the wood base and the floor beneath it. This time it performed the action of racking-out the VCB unit perfectly. This is shown in Fig. 12. The next thing was to perform a rake-out operation. A hoe handle was purchased and a 1.5' section was cut from the top end. The top of the pneumatic cylinder came with a solid aluminum cylinder. This was unscrewed off. The pneumatic cylinder shaft was $\varnothing=20 \mathrm{~mm}$ so a $\varnothing=19 \mathrm{~mm}$ $(\varnothing=20 \mathrm{~mm}$ not available) drill bit was purchased and a 3 " deep hole drilled into the $1.5^{\prime}$ hoe handle. The pneumatic cylinder shaft was pushed into this hole. This enabled extending the pneumatic cylinder shaft length. The pneumatic cylinder was actuated, and it performed the rake-in operation successfully as shown in Fig. 12 right. Therefore, just two $\varnothing=6 \mathrm{~mm}$ holes need to be drilled just in front of the switchgear to operate this Switchgear Switching Safety System (SSSS). This is not very visible and does not affect the aesthetics of the switchgear room.

The next step was to use the SSSS to switch a pushbutton which is common for new switchgears where a push button triggers a motor to activate the triggering of a HV switchgear. It must be noted that even though there is little human effort exerted to switch these HV switchgears, the danger from a mechanical malfunction within the HV switchgear is the same. Like in the case described in the Literature Review above where the shaft to close the switchgear had a lack of grease and it was slow in closing the circuit. Therefore, it is still important to switch such HV switchgears from a safe distance away. A small pneumatic cylinder was purchased and the $0.25 \mathrm{HP}$ air pump can optimally be used for activating such a cylinder but it can also be operated with the $2.5 \mathrm{HP}$ air pump. This was successfully accomplished as shown in Fig. 13 where the pneumatic cylinder was held in place with a magnet; specifically the magnetic rotor of a stepper motor. In the experience of this author, this is the strongest magnet around. A car speaker magnet is placed inside the panel to keep this in place. A further improvement is to use two electromagnets, one placed on the inside of the panel, and one placed on the outside. The reason is because these days, the panels are made with very thin steel and magnets do not stick well to such panels. Some panels are also currently made of totally unmagnetic aluminum where such an electromagnet method is a must. There are suction cups these days developed to carry sheet metal but considering their wear and tear issues, the electromagnet solution is still better. Therefore, the push button unit comes with a 5 " cylinder attached to an electromagnet as shown in Fig. 13 plus another electromagnet. The control wooden box of the SSSS already has a 24V DC power supply, therefore these electromagnets can be powered with that power supply with two lengths of standard telephone wires running to the HV switchgear panel: the one with the grey PVC covering with four pairs of twisted cables within.

It must be noted that lots of effort and expense was spent in this research to power the 2.5HP air pump with an inverter connected to the battery of a running car. An extra-long jumper cable was built with $25 \mathrm{~mm}^{2}$ flexible welding cable. The extra length was required because the battery is in the front trunk of the pick-up truck (most common car used by SP) and the control box of Fig. 8 left is placed in the back seat of the pick-up truck. Initially a $3000 \mathrm{~W}$ inverter was purchased; the insides of which are shown in Fig. 7 top right. That should be sufficient because $2.5 \mathrm{HP}$ is:

\section{$2.5 \mathrm{HP} \times 746=1865 \mathrm{~W}$}

But the air pump cannot run. A big mistake was then made in purchasing another $3000 \mathrm{~W}$ and joining them in parallel. This mistake must be reported in this paper so that others do not make the same mistake. Joining the output of two inverters is basically the same as joining two generators. They must be synchronized before joining them. In power stations as well as on O\&G rigs, the method preferred is an incandescent bulb joined to the blue or L3 phase wires of both generators. The live $(\mathrm{L})$ is joined to one generator's B phase wire and the neutral $(\mathrm{N})$ is joined to the other generator's blue phase wire. Incandescent bulbs are unique in being able to withstand a voltage in the $\mathrm{L}$ to $\mathrm{N}$ of even more than $415 \mathrm{~V}$. It must be noted that the maximum momentary voltage when two phases are joined is:

$$
\frac{240}{0.707}=339 \text {, implies max of } 339 \mathrm{X} 2=678 \mathrm{~V}
$$

Then the DC going into the rotor solenoid of one of the generators is tuned up or down. What happens when the $\mathrm{DC}$ is tuned is that the $\mathrm{AC}$ waves coming out from the stator coils will have its frequency varied or the AC waves from this particular generator moves back and 


\section{A System to Ensure Safety while Switching High Voltage Switchgears}

forth relative to the other generator's AC wave. When the bulb shuts off, the two waves are exactly in phase and there is no voltage difference between them to light up the bulb. That is the point where the rotors are exactly in phase or synchronized and at that moment the three phases of the two generators are joined with a contactor.

But for inverters there is no option to move the $\mathrm{AC}$ wave back and forth. Therefore, there is no simple method to synchronize the AC output of two inverters. The only way to fully synchronize the output of two inverters is to do it with a microcontroller. Meaning the $\mathrm{AC}$ output of one inverter must be converted to DC and then a new $\mathrm{AC}$ wave must be created out of that with the microcontroller with respect to the $\mathrm{AC}$ wave of the other inverter.

The next idea is that the local inverters sold locally may be falsifying their capabilities; $3000 \mathrm{~W}$ AC which cannot run a $1865 \mathrm{~W}$ pump. So a $10,000 \mathrm{~W}$ inverter was purchased from Amazon USA (with the specification: Wagan Black EL3748 12V with a peak surge capacity of $20,000 \mathrm{~W}$ ). The spec on it states that it has a surge capacity of $20,000 \mathrm{~W}$ peak. This is good because all motors will have a few seconds where they draw in a large current to overcome inertia of the rotor. But after the long wait for it to arrive, even that inverter cannot run the $1865 \mathrm{~W}$ pump despite using a running big pickup truck's battery as the incoming as shown in Fig. 6 left. A few more studies were made as described below.

The next step was to design and get a manufacturer to build a multi-tap autotran capable of 20A (Fig. 6 right top) and using a microcontroller to make it output $20 \mathrm{~A}$ AC. Meaning as the microseconds increase the tap of the autotran to take the voltage from varies to higher and higher voltage taps. In other words a new type of inverter was being built. But initial experiments damaged some power equipment and therefore it was abandoned since there was a timeline to get the system running.

The $10 \mathrm{~m}$ jumper cables were observed to be slightly hot after the experiment. The jumper cable is $5 \mathrm{~m}$ but the current has to run on the positive and negative jumper so the total length is $10 \mathrm{~m}, A=25 \mathrm{~mm}^{2}$. Therefore, the resistance is $6.84 \times 10^{-3} \Omega$ using equation (3) below. The meter on the inverter indicated that the current going into it was 240A. Therefore, the power loss is $\mathrm{P}_{\text {loss }}=394 \mathrm{~W}$ as shown below:

$$
\begin{aligned}
R & =\frac{\rho L}{A} \\
R & =\frac{0.0171 \times 10}{25} \\
R & =6.8410^{-3} \Omega
\end{aligned}
$$

$$
\begin{gathered}
\mathrm{P}_{\text {loss }}=\mathrm{I}^{2} \mathrm{R} \\
\mathrm{P}_{\text {loss }}=\left(240^{2} \times 6.84 \times 10^{-3}\right)=393.98 \text { watts } \approx 394 \text { Watts }
\end{gathered}
$$

The pump draws $8.1 \mathrm{~A}$, therefore:

$$
\begin{gathered}
P=V I \\
P=240 V \times 8.1 A=1944 W
\end{gathered}
$$

Which requires a jumper cable capable of carrying:

$$
\mathrm{I}=\frac{\mathrm{P}}{\mathrm{V}}=\frac{1944}{11}=176 \mathrm{~A}
$$

From the cable carrying capacity table of IEE, this requires a $70 \mathrm{~mm}^{2}$ sized jumper cable [4]. The autotran had a capacity of $20 \mathrm{~A}$ and is therefore incapable of carrying 176A. To purchase $10 \mathrm{~m}$ of $70 \mathrm{~mm}^{2}$ jumper cable and an autotran which can handle $>176 \mathrm{~A}$ would cost too much money.

It was then decided to just purchase a genset; the red one in Fig. 8 middle bottom and left, below the wooden box. It is rated at $2000 \mathrm{~W}$, just slightly above the power $1865 \mathrm{~W}$ required by the air pump. Compared to all the problems above, the genset worked perfectly. It was as if the power problem did not exist after that.
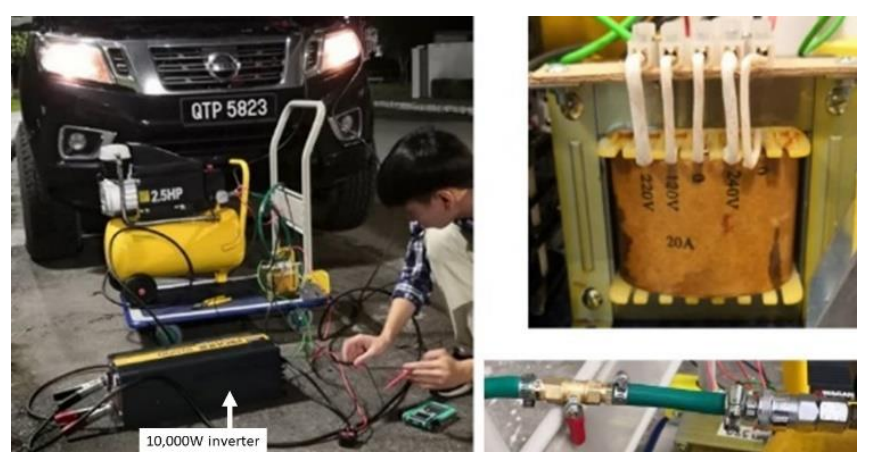

Fig. 6: On left is the testing of the 2.5HP pump powered by the $10,000 \mathrm{~W}$ inverter. On the right top is a 20A capacity autotran. 


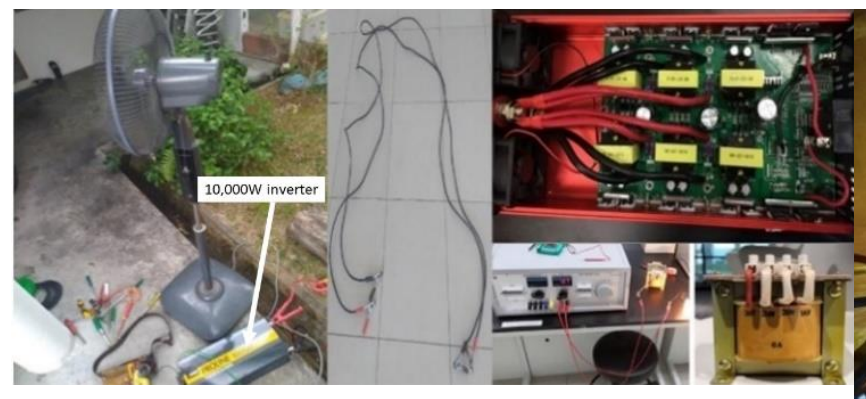

Fig. 7: On the right is the $10,000 \mathrm{~W}$ inverter running a fan successfully. Middle is the extra-long jumper cable built with $25 \mathrm{~mm}^{2}$ pure $\mathrm{Cu}$ flexible cable. Bottom left is the testing of another autotran with multiple voltage taps to test a method to improve the inverter design.
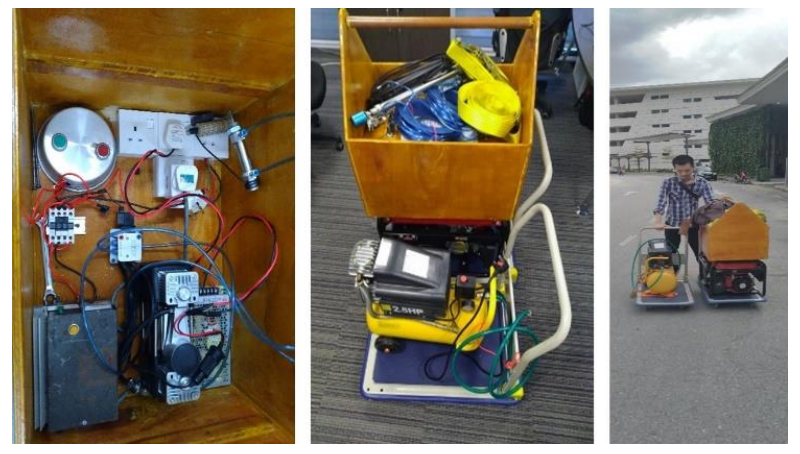

Fig. 8: On the left is the full circuit. The middle and right is the whole system placed on two trolleys.

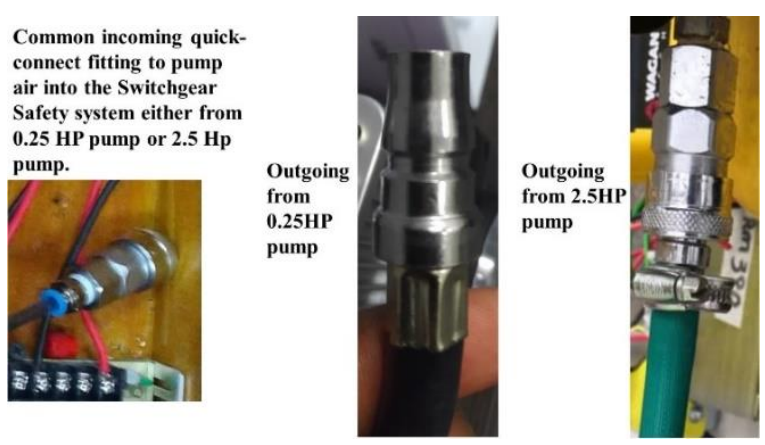

Fig. 9: The quick-connect to enable easy switching between the $0.25 \mathrm{HP}$ pump which can be energized from a car cigarette lighter and the 2.5HP pump which must be powered with a genset.

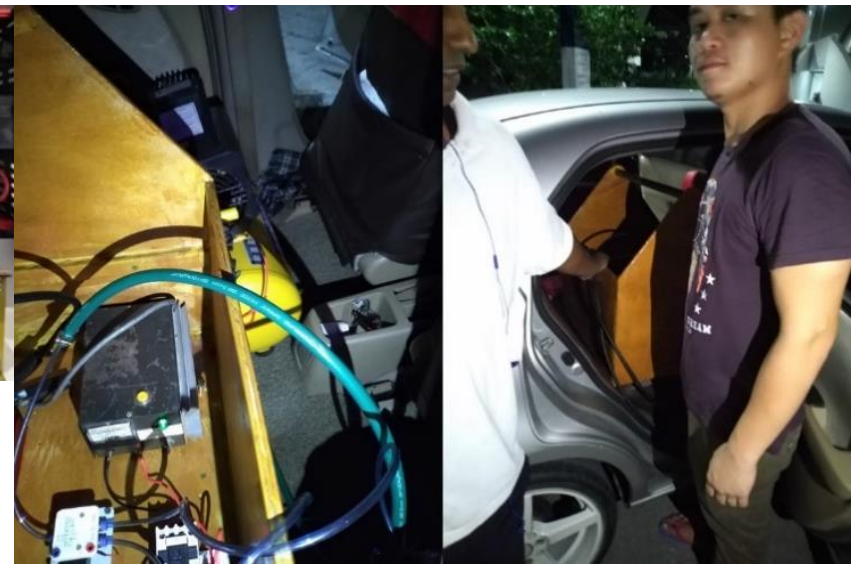

Fig. 10: The whole system can fit even in a in a small car.
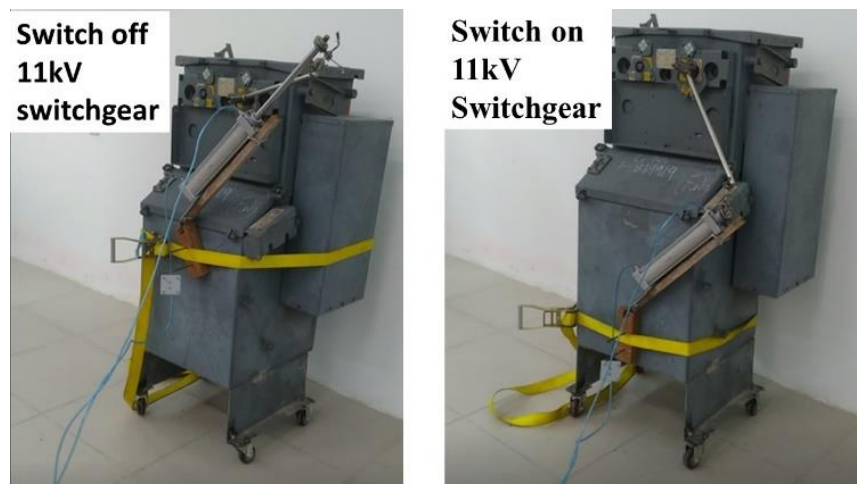

Fig. 11: Taken the moment the successful switch off happened (left) and the moment switch on happened (right) of the $11 \mathrm{kV}$ Lucy brand OCB.
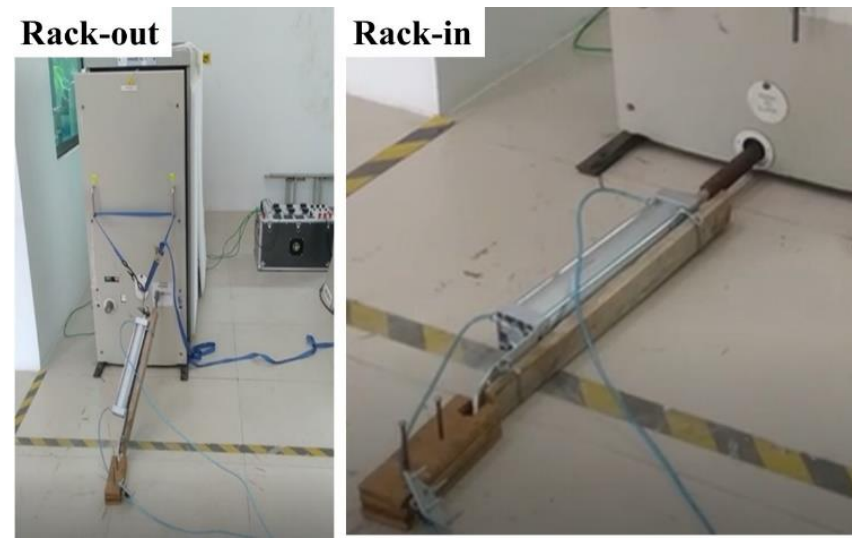

Fig. 12: Successful rack-out (left) and rack-in (right) of HV VCB. 


\section{A System to Ensure Safety while Switching High Voltage Switchgears}

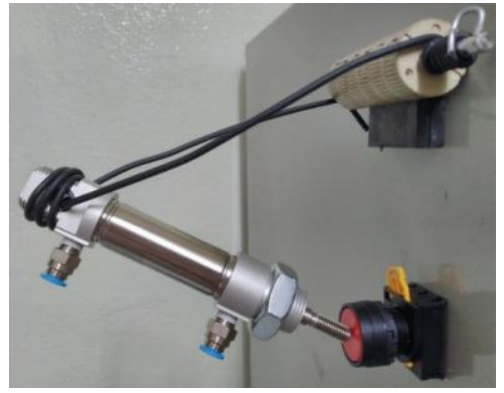

Fig. 13: The jig to enable switching on and off the most modern motorized HV switchgears.

\section{CONCLUSION}

This research successfully met its initial objective of switching the Lucy brand $11 \mathrm{kV}$ switchgear. The SSSS was later used to successfully rake-in and rake-out $33 \mathrm{kV}$ type HV switchgears. The SSSS was also used to successfully trigger a push button which most modern HV switchgears are using from up to $25 \mathrm{~m}$ away.

It has to be noted that building of such a system has been tried by the LEA since its inception but research activities are best suited for university lecturers whose focus is to produce research. This author previously noticed that the LEA could not design a proper micro-hydro while university lecturers could do so. The reason for such a scenario is that in large electric corporations there are the yearly reviews of engineers and often that review is weighted to income generated for the company and safety issues are falsely not taken to not cost a lot of money. It is for this reason that university lecturers can perform such research better. It is often hard to justify the research contribution financially till it is marketed much later on. Therefore, in such corporations, the engineers will quickly jump ship to power generation and distribution sections where financial contribution can more easily be displayed.

This research brought about much learning for all the participants and authors. The final Switchgear Safety System developed can be repaired all over Sarawak even in small motorcycle repair shops of rural villages.

The finalized system needs two trolleys (Fig. 8 right and middle) to move to and from the pick-up truck which is the standard car of SPs. The wooden box is placed in the back seat of the pick-up truck, the yellow 2.5 HP pump is placed between the passenger seat and the back seat and the genset is placed in the trunk. The SP just carries the pneumatic cylinder and truck ratchet rope in his/her two hands to the HV switchgear and comes back to the pickup truck to trigger the actuation.

\section{ACKNOWLEDGEMENT}

This work was carried out with a grant from University Research Grant from University of Technology Sarawak (UTS), School of Engineering Technology (SET), CRISD with reference number: UCTS/RESEARCH/<2/2018/12>(01).

\section{REFERENCES}

[1] Park, S. D. (2019, March). Painful Memories of an Electrical Accident. In 2019 IEEE IAS Electrical Safety Workshop (ESW) (pp. 1-4). IEEE.

[2] Prashobh Karunakaran; Mohammad Shahril Osman; Ian Rino Anak Boniface; Atif Norzan Shah (2018). Development of a system to improve safety in switching of high voltage circuit breakers, IEEE Xplore, Electronic ISBN:978-15386-1887-5.

[3] Karunakaran P. Electrical Power Simplified, [Kindle] ASIN B087XBNXV3. ISBN: 978-15462-6246-6 (sc), 978-1-5462-6247-3(e), 2015,2018 .

[4] Chowdhury, A., \& Koval, D. (2011). Power distribution system reliability: practical methods and applications (Vol. 48). John Wiley \& Sons.

[5] Pourmovahed, A., Beachley, N. H., \& Fronczak, F. J. (1992). Modeling of a hydraulic energy regeneration system: Part I-analytical treatment.

[6] Hazel, T., \& Robb, G. (2012, June). Basic design criteria for switchgear and MCC selection. In 2012 Petroleum and Chemical Industry Conference Europe Conference Proceedings (PCIC EUROPE) (pp. 1-8). IEEE.

[7] Karunakaran, P., Osman, M. S., Karunakaran, P., Karunakaran, S., Karunakaran, A., Lee, M. D. \& John, A. (2020). HV Switchgear Switching System. Asian Journal of Convergence in Technology (AJCT), ISSN, (2350-1146), 77-85.

[8] Diendorfer, G., Schulz, W., \& Rakov, V. A. (1998). Lightning characteristics based on data from the Austrian lightning locating system. IEEE Transactions on Electromagnetic Compatibility, 40(4), 452-464.

[9] Karunakaran, Prashobh; Osman, M. S.; Karuppanna, V.; Cheng, S. C.; Lee, M.D.; John, A.; Hieng, T. K. (01 January 2021). A High Voltage Switchgear Switching System. IEEE Xplore, Electronic ISBN:978-1-7281-9744-9.

[10] Yokoyama, S., Miyake, K., Suzuki, T., \& Kanao, S. (1990). Winter lightning on Japan Sea coastdevelopment of measuring system on progressing feature of lightning discharge. IEEE Transactions on Power Delivery, 5(3), 1418-1425. 
[11] Campbell, L. C. (1989, April). HV circuit breaker contacts. In IEE Colloquium on Electrical Contacts (pp. 8-1). IET.

[12] Karunakaran, Prashobh; Osman, M. S., Karuppanna, V., Cheng, S. C., Djun, L. M., John, A., \& Hieng, T. K. (01 September 2020). Design and Building a High Voltage Switchgear Safety System. IEEE Xplore. Electronic ISBN:978-17281-4988-2, CD:978-1-7281-4987-5, Print on Demand (PoD) ISBN:978-1-7281-4989-9

[13] Koch, D. (2003). SF6 properties, and use in MV and HV switchgear. Cahier technique, 188.

[14] Prashobh Karunakaran; Mohd Shahril Osman; Alvin K.S. Lau; Man Djun Lee; Pradeep Kumar (06 September 2018). Underwater Electricity Transmission using Electric Cables Suspended within Carbon Steel Pipes, IEEE Xplore, Electronic ISBN:978-1-5386-3243-7.

[15] Karunakaran, P. (2018). Electrical Power Simplified. AuthorHouse.

[16] Skinner, S. J., \& Kilner, J. A. (2003). Oxygen ion conductors. Materials Today, 6(3), 30-37.

[17] Karunakaran, Prashobh; Osman, M. S.; Karuppanna, V.; Cheng, S. C.; Lee, M. D.; Richard, A.; Lau, A. K. S. (03 August 2020). Electricity Transmission Under South China Sea by Suspending Cables Within Pipes. IEEE Xplore. Electronic ISBN:978-1-7281-6221-8.

[18] Dervos, C. T., Vassiliou, P., \& Mergos, J. A. (2007). Thermal stability of SF6 associated with metallic conductors incorporated in gas insulated switchgear power substations. Journal of Physics D: Applied Physics, 40(22), 6942.

[19] Bhattacharya, Subhashish. High MegaWatt MV Drives, Dept. of ECE, FREEDM Systems Center, NC State University.

[20] Bui, B. D., Uchiyama, N., \& Simba, K. R. (2016). Contouring control for three-axis machine tools based on nonlinear friction compensation for lead screws. International Journal of Machine Tools and Manufacture, 108, 95-105.

[21] Petkov, E., \& Angelov, V. (2020, June). Virtual Reality Training System for Specialists Who Operate on High-Voltage Switchgears in an Oil Plant in Russia. In Proceedings of the 21st International Conference on Computer Systems and Technologies' 20 (pp. 266-269).

[22] Alexander Jacobsen Jardim, P., Tore Rein, J., Haveland, Ø., Rykkje, T. R., \& Impelluso, T. J. (2019). Modeling crane-induced ship motion using the moving frame method. Journal of Offshore Mechanics and Arctic Engineering, 141(5).

[23] Doerry, N., \& Amy, J. (2017, August). Electric ship power and energy system architectures. In 2017 IEEE Electric Ship Technologies Symposium (ESTS) (pp. 1-64). IEEE.

[24] Rankin, A. (2017). Energy efficiency is a security issue: Australia is overly dependent on oil and should look to new technologies. Australian Rationalist, The, 107, 37-38.

[25] Rengifo, J., Romero, J., \& Aller, J. M. (2018, October). Efficiency evaluation of induction motors supplied by vfds. In 2018 IEEE Third Ecuador Technical Chapters Meeting (ETCM) (pp. 1-6). IEEE.

[26] Lee, R. H. (1982). The other electrical hazard: Electric arc blast burns. IEEE Transactions on Industry Applications, (3), 246-251.

[27] Mutyam, N., Saikumar, T. S., \& Soppari, B. (2020). Design of Sequential Electro-Pneumatic System. In International Conference on Emerging Trends in Engineering (ICETE) (pp. 610-615). Springer, Cham. 